\title{
Low Temperature Machining of Nitrile Rubber
}

\section{Nayak Rajesh, Nayak Akshay and Shetty Raviraj*}

\author{
Department of Mechanical and Manufacturing Engineering, \\ Manipal Institute of Technology, \\ Manipal Academy of Higher Education, Manipal, India, Karnataka- 576104 \\ *Email: rr.shetty@ manipal.edu \\ Phone: +918217274760
}

\begin{abstract}
This paper presents an innovative methodology to improve machining of nitrile rubber. The research comprises of turning of nitrile rubber under ambient (dry) and lowtemperature (dry ice) condition against HSS cutting tool. Individual machining force data for all the tests were documented with the help of a Kistler dynamometer. The low temperatures freeze the material previous to machining so that it cannot alter or adhere to the cutting edge, thus resulting in low wear on the edge and improved machining. To achieve a stable condition for the rubber machining, a mandrel was designed to hold the rubber workpiece. It was observed that $36.19 \%$ reduction in cutting force, $6.08 \%$ decrease in radial force and $23.3 \%$ drop in feed force were obtained when cutting was made at low-temperature machining as compared to dry cutting with cutting speed increased from $162.58 \mathrm{~m} / \mathrm{min}$ to $226.19 \mathrm{~m} / \mathrm{min}$, with $1 \mathrm{~mm}$ depth of cut and tool feed of $0.5 \mathrm{~mm} / \mathrm{rev}$. This concludes that a remarkable decrease in cutting force value can be obtained by adopting low-temperature cooling. Thus, this new approach concludes that dry ice machining of nitrile rubber should be amended in a directive to acquire better machining results.
\end{abstract}

Keywords: Dry ice; machining forces; chip morphology.

\section{INTRODUCTION}

Rubber components are most commonly manufactured by either moulding or curing process. In both approaches the main inadequacies are initial cost and suppleness to design variations. A substitute method to manufacture rubber product is material removal practice. Since rubber poses low modulus elasticity and suppleness in nature, machining of rubber finds a challenging development. Rubber exhibits a highly nonlinear stress-strain relationship as compared to metals. Rubbers are able to recover to an un-deformed state after a large deformation upon removal of the load. Rubbers have no yield point in the stress-strain curve and they are highly non-linear at large strains.

The elastic modulus and tensile strength of rubber are also low compared to metals. Rubbers have better fatigue resistance and good energy absorption capability due to their high elasticity. The material properties of rubber change significantly with temperature variation. Poisson's ratio of rubber is close to 0.50 (nearly incompressible). The coefficient of friction for rubber surfaces is relatively high compared with a metal to metal interface. Rubbers are elastic, durable, leak-proof, and unaffected by corrosion. The moldability of rubbers allows for their use in a wide range of applications such as hoses, belts, tubes, engine mounts, wiper blades, footwear, toys, and tires. In dry 
machining circumstances though, rubber is tough to clamp using work holding device in machine tools. Low-temperature machining of rubber components has not been extensively presented in production. Difficulties include unsteadiness of the cutting practice causing reduced material removal rate, gripping of rubber workpiece and building machining environment for low-temperature cutting process. These difficulties in regular cutting circumstances enforce the development of inventive machining techniques.

Low-temperature machining has conveyed significant benefits to machining of different metals. In low-temperature machining of rubber little research has been directed. Jin and Murakawa [1] conducted early research on elastomer machining. The experiments were carried out at high speed and with large helix angle. The large tool helix and rake angles for manufacturing precision elastomeric parts resulted in better metal removal process. Shih et al. [2] investigated the machining of elastomers with sharp woodworking tools and under cryogenic conditions. With a good selection of end mill geometries, machining parameters and fixture design, uncontaminated grooves can be machined in elastomers. It was also revealed that cryogenic cooling of an elastomer workpiece was advantageous in accomplishing a smooth machined surface. Shih's research team also planned out experiments to analyse the effect of diverse cutting factors on chip morphology, machined product surface state and magnitude of cutting forces. They established that different forms of chip were generated because of the substantial influence of machining speed, tool feed and tool rake angle in rubber machining.

Strenkowski et al. [3] deliberated the consequence of cutting tool rake angle, clearance angle, tool feed, machining speed and workpiece temperature during orthogonal cutting experiments. According to them, to gain an improved surface finish, the rake angle of the cutting tool possessed an imperative role. Results of Dhar et al. [4,5] indicated the possibility of substantial reduction in cutting forces by favourable chips formation in turning AISI 1040 and AISI 4320 steels with cryogenic cooling by liquid nitrogen jets. Rodkwan et al. [6] conducted orthogonal rubber cutting experiments and established that orthogonal cutting was the most simplified form without neglecting the complex material aspects associated with the machining process. They also studied the effects of various machining parameters on chip morphology, machined surface roughness, and the associated machining forces were examined. Feed and rake angle were found to have significant effect on the types of chips generated during orthogonal cutting. Long and continuous ribbon-like chips and corresponding smooth machined surfaces were produced for high-feed speed conditions and large rake angle tools.

Because of its low modulus elasticity and flexibility in environment shape machining of elastomers faces a challenging process. However, in ambient machining conditions, rubber workpiece is difficult to support using work holding devices in machine tools. These problems in normal cutting conditions impose improvement of ingenious cutting techniques. In the opinion of overhead facts, an effort is being made to investigate the machinability of nitrile rubber.

This paper presents an innovative methodology to improve machining of nitrile rubber. The research consists of turning of nitrile rubber under ambient (dry), and lowtemperature (dry ice) condition against high-speed steel (HSS) single-point cutting tool. The attention of the study in this paper is on understanding the influence of machining speed, depth of cut and tool feed on the magnitude of forces and chip shape in the machining of rubber. 


\section{EXPERIMENTAL SETUP}

The material used for the experiments was nitrile rubber (NBR). According to ASTM testing [7], the specifications and mechanical properties of the test sample is shown in Table 1. The selected geometry for the experiments was a tube workpiece with $45 \mathrm{~mm}$ in outer diameter and $60 \mathrm{~mm}$ in length. In the course to analyse the consequence of lowtemperature under material machinability, samples were cooled through immersion in a container with dry ice. The ambient as well as low-temperature condition experiments were performed in a PSG A141 lathe $(2.2 \mathrm{KW})$ as shown in Figure 1 (a) and (b). The experimental values for three levels of cutting speed, tool feed and depth of cut are shown in Table 2.

Table 1. Specifications and mechanical properties of test sample

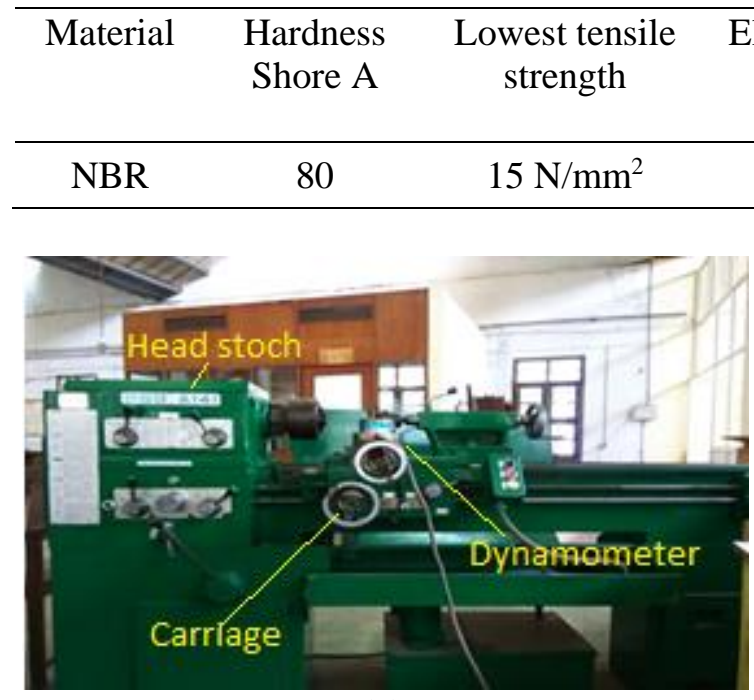

(a)

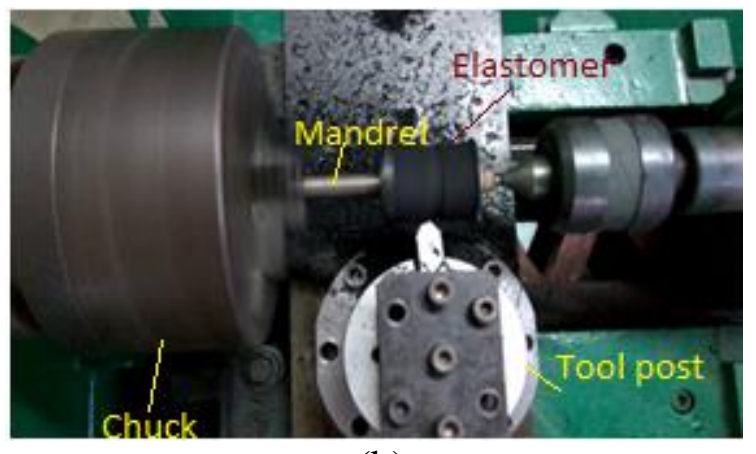

(b)

Figure 1. (a) PSG A141 lathe machine and; (b) experimental set-up for ambient temperature machining process.

Table 2. Experimental conditions.

\begin{tabular}{|c|c|c|}
\hline \multicolumn{2}{|c|}{$\begin{array}{l}\text { Machine specification: } \\
\text { Work specimen: } \\
\text { Cutting tool: }\end{array}$} & $\begin{array}{l}\text { PSG A141 lathe }(2.2 \mathrm{KW}) \\
\text { Nitrile rubber } \\
\text { Single point high speed steel cutting tool }\end{array}$ \\
\hline \multirow{3}{*}{$\begin{array}{l}\text { Process } \\
\text { Parameters }\end{array}$} & $\begin{array}{l}\text { Feed rate } \\
(\mathrm{mm} / \mathrm{rev}) \text { : }\end{array}$ & $0.25,0.375$ and 0.5 \\
\hline & $\begin{array}{l}\text { Depth of cut } \\
(\mathrm{mm}) \text { : }\end{array}$ & $0.5,0.75$ and 1.0 \\
\hline & $\begin{array}{l}\text { Cutting speed } \\
(\mathrm{m} / \mathrm{min}) \text { : }\end{array}$ & $113.10,162.58$ and 226.19 \\
\hline \multicolumn{2}{|c|}{ Machining environment: } & Dry and with dry ice condition \\
\hline
\end{tabular}

The elastic modulus (1 10 MPa) of the nitrile rubber is low as matched with steel [8]. Rubber reveals large elastic distortion before separation. In previous 
investigations $[9,10]$, the researcher recommended a stable mandrel for gripping the rubber workpiece. The mandrel was designed to grip the cylindrical workpiece and to hold between the centres in the lathe. The elastomer tube is fixed to a mandrel with through screws for workpiece stability as shown in Figure 2. The lathe chuck grabbed the mandrel in order to avoid deformation of the flexible workpiece. The machining experiments were carried out by high speed steel under ambient and low temperature conditions.

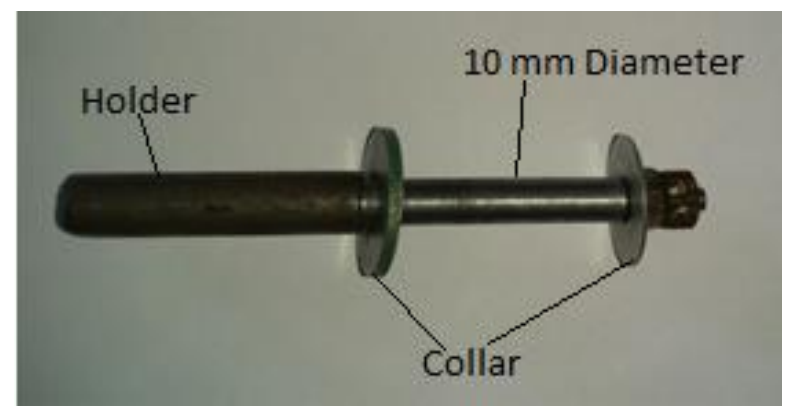

Figure 2. Mandrel design

\section{Cooling using Dry Ice}

The carbon dioxide $\left(\mathrm{CO}_{2}\right)$ in solid form is dry ice, is colourless, non-combustible, with a sour zesty odour. The low-temperature and uninterrupted redirection to a gas create dry ice an effective coolant. Dry ice does not leave the residue upon of state and is colder than water ice. The nitrile rubber workpiece fixed to the fixture is dipped in the dry ice bath for 5 minutes as shown in Figure 3 (a). The rubber workpiece absorbs the dry ice and becomes brittle and immediately after it is held using a three-jaw chuck in the lathe as shown in Figure 3 (b), and the machining process for one level of machining parameters are carried out as the temperature of the workpiece decreases. The machining process is repeated by again dipping the workpiece in dry ice container and fixing the workpiece to the chuck for different cutting parameters.

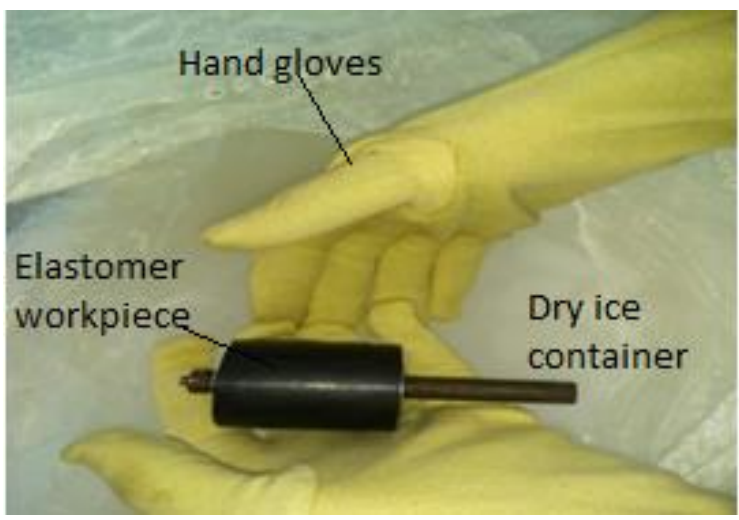

(a)

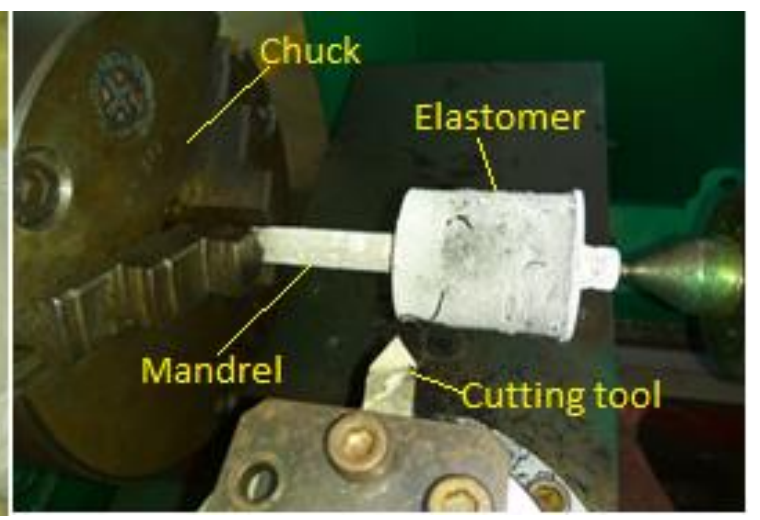

(b)

Figure 3. (a) Dry ice bath and (b) experimental set-up of low temperature machining process. 
To measure and record the force components, a 4-component force and torque measuring piezoelectric dynamometer were attached to the tool post for extracting the cutting, feed, and radial forces. A 4-channel control amplifier and a computer-based Dynoware software were utilised for data achievement and examination.

\section{RESULTS AND DISCUSSIONS}

\section{Machining Forces}

The cutting forces vary to a significant extent depending upon the physical and mechanical properties of the material [11]. The force components were measured and analysed. It was detected that the machining forces amplified through the escalation in machining speed and tool feed. The extent of cutting forces for ambient machining increased with the rise in tool feed and machining speed as there were no control over the heat developed during machining and no technique was implemented to move the chips away from the tooltip. There was a decrease in the values of cutting forces observed for machining using low-temperature machining with the increase in tool feed and cutting speed. This is due to fact that the decrease in temperature of the workpiece was found to be effective in changing the cutting environment and the cooling cutting zone efficiently.

The three measured and recorded forces (cutting, feed, radial) were plotted with three cutting parameters to understand the variation in low-temperature condition compared to dry condition. Figure 4, 5 and 6 plot show the deviation of cutting force, radial force and feed force at three different cutting speeds in rubber machining at three different feeds and depths of cut. The plots show similar trend of variation in cutting force obtained in low-temperature results with three different cutting speeds. The magnitude of forces decreases for increases in machining speed from $113.10 \mathrm{~m} / \mathrm{min}$ to $226.19 \mathrm{~m} / \mathrm{min}$. The decrease in the magnitude of cutting force is mainly because, when the rubber is in low-temperature condition its stiffness and Young's modulus increase thus, when the cutting speed increases the force value decreases for increase in cutting speed.

Figure 4 (a), (b) and (c) show the measured cutting force, radial force and feed force components as a function of tool feed for three levels of depth of cut at cutting speed of $113.10 \mathrm{~m} / \mathrm{min}$ under ambient and low-temperature machining condition. It is evident from the graph in Figure 4 (a) that the increase in cutting force is $19.56 \%$ at $0.25 \mathrm{~mm} / \mathrm{rev}$ tool feed, and $19.7 \%$ at $0.5 \mathrm{~mm} / \mathrm{rev}$ cutting feed, when the depth of cut increased from 0.5 to $1 \mathrm{~mm}$, respectively. The increase in radial force in Figure 4 (b) is $44.8 \%$ at $0.5 \mathrm{~mm} / \mathrm{rev}$ tool feed and $1 \mathrm{~mm}$ depth of cut. The feed force in Figure 4 (c) increases to $25.65 \%$ at $0.5 \mathrm{~mm} / \mathrm{rev}$ tool feed and $1 \mathrm{~mm}$ depth of cut. With the increase in the depth of cut, the tool indents more into the workpiece and the width of cut becomes reasonably high [12-13]. This effect increases the chip section in contact with the tool and in turn increases cutting forces in the feed direction to cut the chip. Therefore, cutting forces increases as the depth of cut increases. 


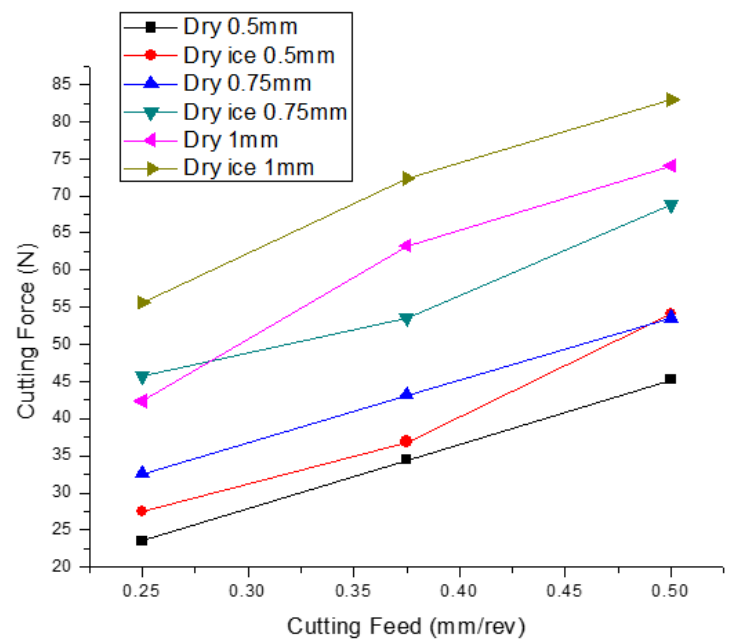

(a)

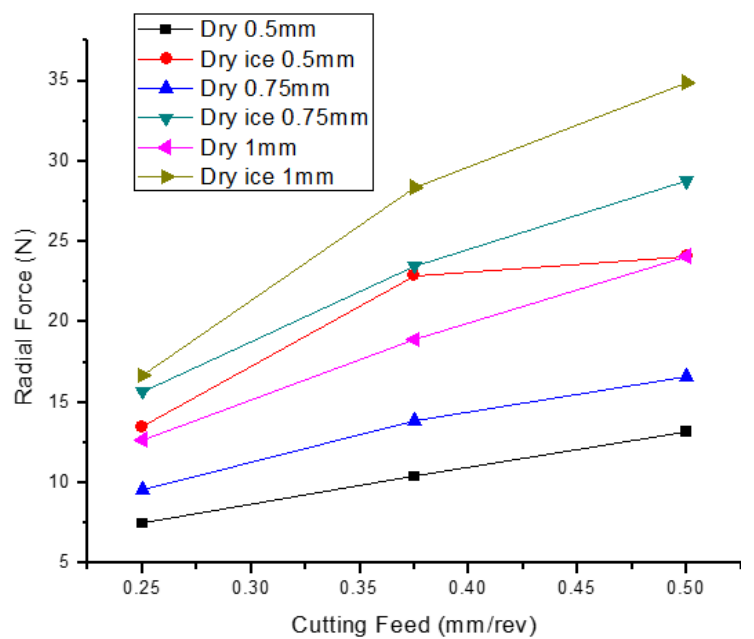

(b)

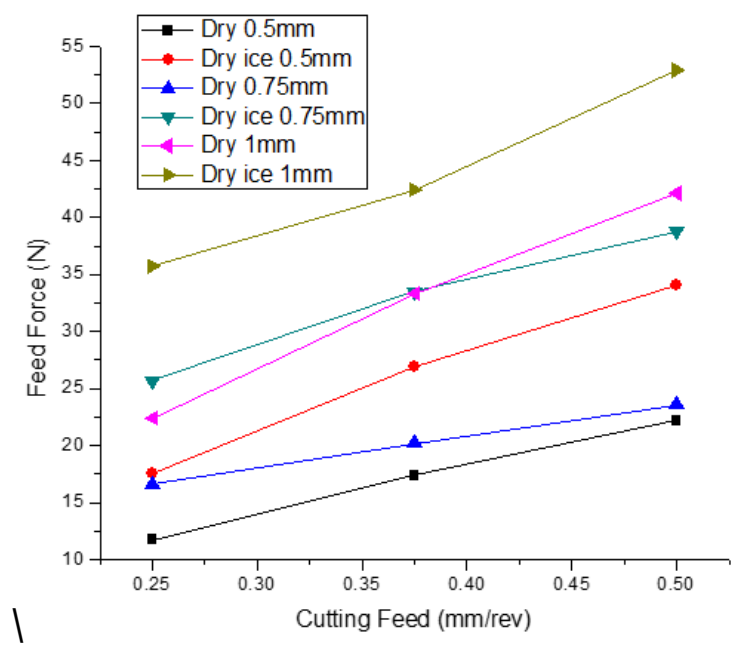

(c)

Figure 4. Comparison of (a) cutting force, (b) radial force and; (c)feed force with tool feed at cutting speed of $113.10 \mathrm{~m} / \mathrm{min}$ for various depths of cut

The comparison of the magnitude of machining force values at a machining speed of $162.58 \mathrm{~m} / \mathrm{min}$ and at three different tool feeds under dry and low-temperature condition is shown in Figure 5. It is obvious from graph of Figure 5 (a) that the fraction variances in cutting force at $0.25 \mathrm{~mm} / \mathrm{rev}$ tool feed are 18.6 and 13.7 at $0.5 \mathrm{~mm} / \mathrm{rev}$ tool feed for $0.5 \mathrm{~mm}$ and $1 \mathrm{~mm}$ depth of cut, respectively. The increase in radial force from Figure 5 (b) is $25.8 \%$ at $0.5 \mathrm{~mm} / \mathrm{rev}$ tool feed and $1 \mathrm{~mm}$ depth of cut. The feed force in Figure 5 (c) increases to $18 \%$ at $0.5 \mathrm{~mm} / \mathrm{rev}$ tool feed and $1 \mathrm{~mm}$ depth of cut. The reason is that when rubber is dipped in dry ice, the rubber workpiece turns brittle owing to the low-temperature influence formed by the dry ice, as a result of which hardness also increases which is responsible for the increase in cutting forces in low-temperature machining. 


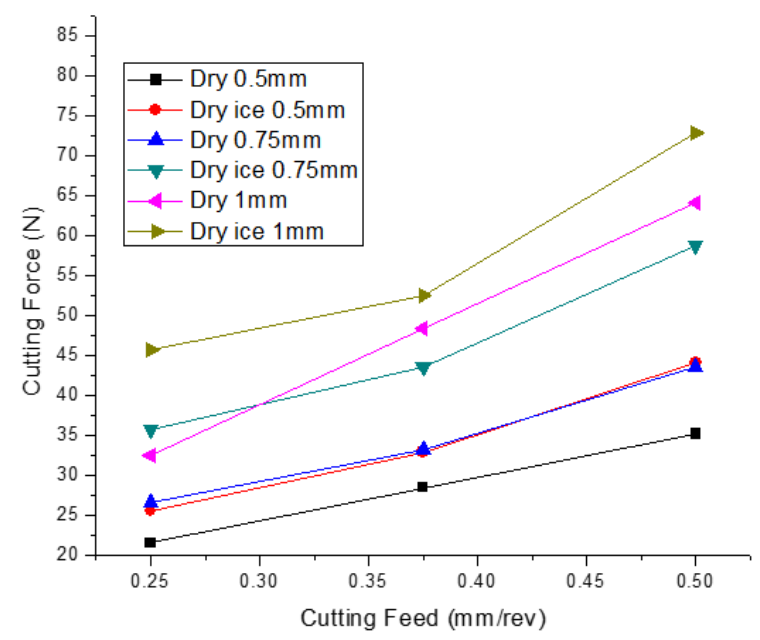

(a)

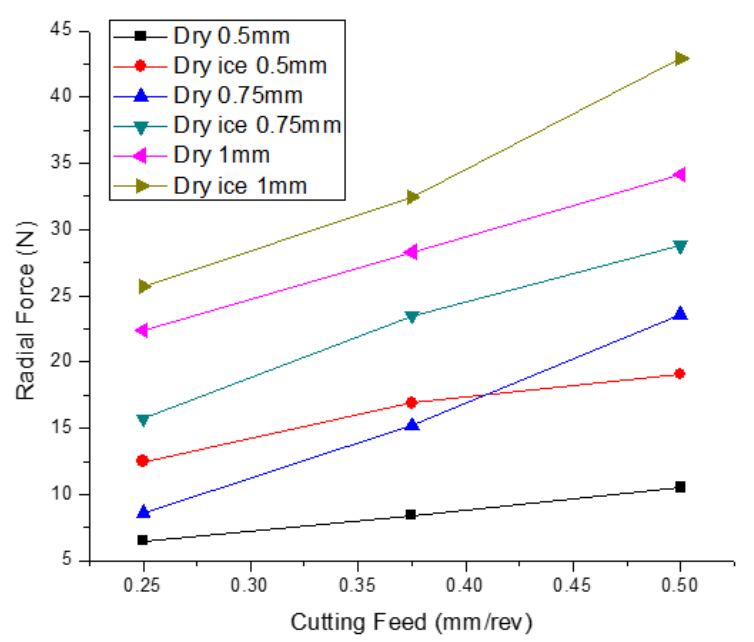

(b)

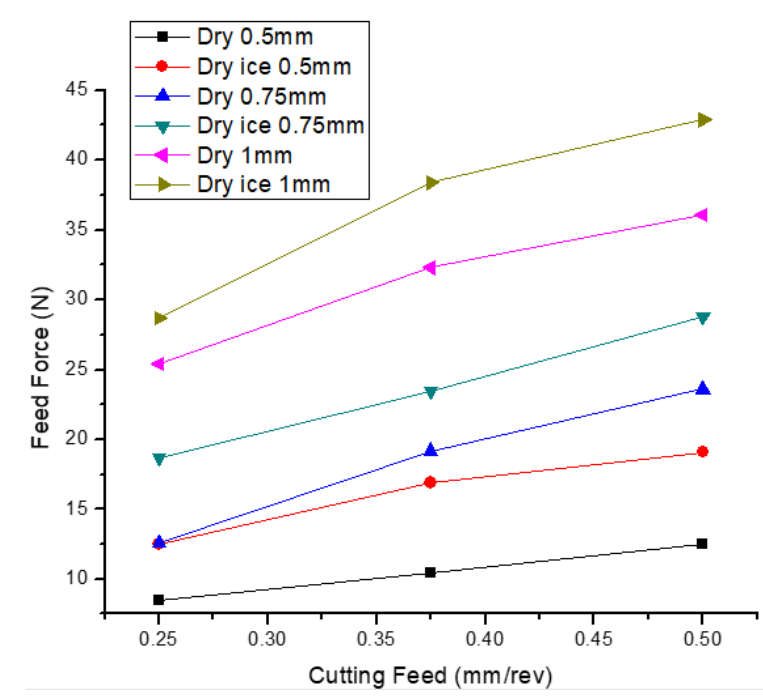

(c)

Figure 5. Comparison of (a) cutting force, (b) radial force and; (c) feed force with tool feed for cutting speed of $162.58 \mathrm{~m} / \mathrm{min}$ at various depths of cut.

The magnitude of turning force values for dry and low-temperature machining of rubber at a cutting speed of $226.19 \mathrm{~m} / \mathrm{min}$ and at three different tool feeds is shown in Figure 6. It is clear from the figure that the increase in cutting force at $0.5 \mathrm{~mm}$ depth of cut is 8.79 and $9.32 \%$ at $1 \mathrm{~mm}$ depth of cut for tool feed $0.5 \mathrm{~mm} / \mathrm{rev}$ as shown in Figure 6 (a). The increase in radial force in Figure 6 (b) is $17.08 \%$ at $0.5 \mathrm{~mm} / \mathrm{rev}$ cutting feed and $1 \mathrm{~mm}$ depth of cut. The feed force increases to $18.83 \%$ at $0.5 \mathrm{~mm} / \mathrm{rev}$ tool feed and $1 \mathrm{~mm}$ depth of cut as shown in Figure 6 (c). It is evident from the graph that cutting speed of $226.19 \mathrm{~m} / \mathrm{min}$ gives better result than other combinations. The variation in radial and feed force values increases when the workpiece is cooled but the variation increase in force values are within $10 \%$ for low cutting feed and depth of cut. With the increase in feed rate the section of the sheared chip thickness increases because the workpiece resists rupture more and requires larger force for chip removal [14-15]. Therefore, cutting forces increases as the feed rate increases. 


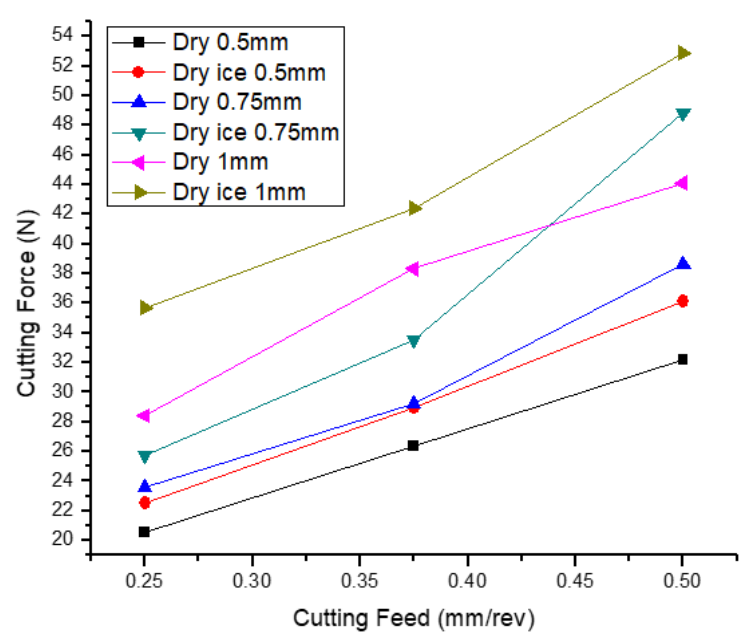

(a)

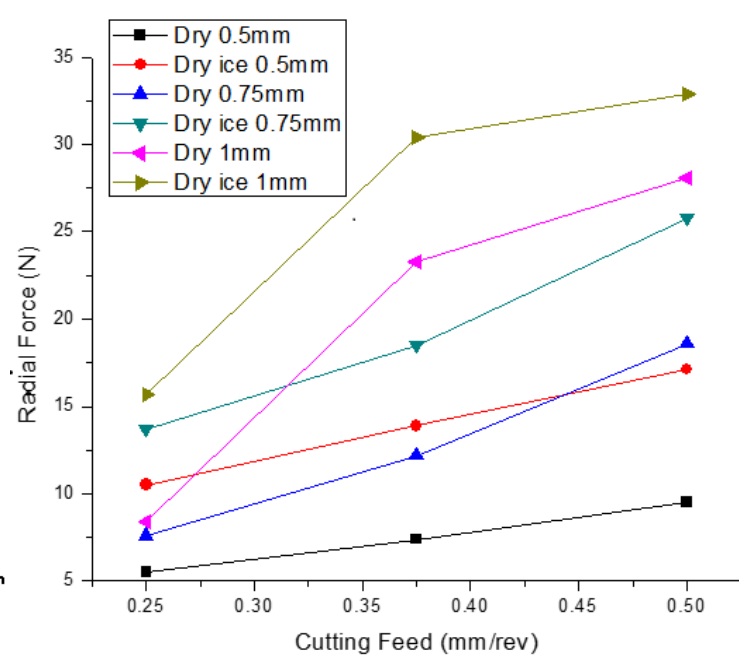

(b)

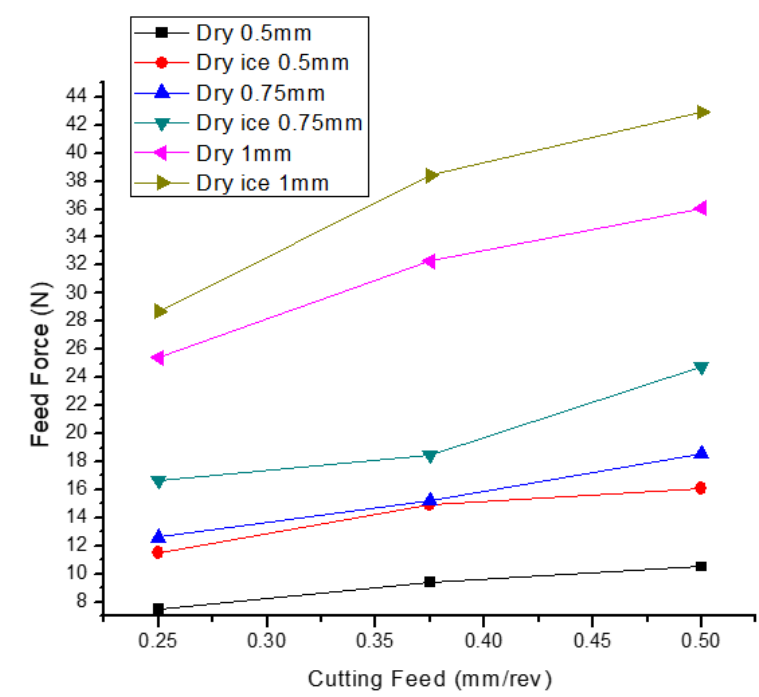

(c)

Figure 6. Comparison of (a) cutting force, (b) radial force and; (c) feed force with tool feed for cutting speed of $226.19 \mathrm{~m} / \mathrm{min}$ at various depths of cut.

\section{Chip Morphology}

It is accredited from the principle of metal cutting that an inspection of machined chip shapes delivers a reasonable way of analysing the cutting physiognomies of a material [11]. The shape of the chip formed in machining is the most important parameter influencing the efficiency of production in the cutting industry. Chip length is one important factor which defines the surface roughness and surface integrity as well as machinability of nitrile rubber [13]. It describes the time of contact with the workpiece. If the contact time with the workpiece is more, it leads to tool wear due to abrasion and diffusion, resulting in shorter tool life.

In the case of nitrile rubber turning, when the cutting tool touches the workpiece and penetrates inside it, the shear deformation starts and the primary zone moves forward as the cutting proceeds. The cutting parameters affect the chip length which replicates the characteristics of chip contact with the tool. The chip length at different 
cutting speeds is shown in Figure 7 (a) to (c). When chip separation takes place at low speed $(113.10 \mathrm{~m} / \mathrm{min})$ it is observed that the chip length is shorter whereas at cutting speed of $162.58 \mathrm{~m} / \mathrm{min}$ the chip length increases but at the top surface chip we could observe the separation of the surface which results into a discontinuous chip. The chip separation at $226.18 \mathrm{~m} / \mathrm{min}$ results in a continuous chip at tool feed of $0.25 \mathrm{~mm} / \mathrm{rev}$ and the movement of the chip over the surface is away from the cutting region. When the continuous chips are formed they lead to a better surface finish of the rubber workpiece in low-temperature cutting condition. The chip length increases with an increase in cutting speed in low-temperature machining. This is due to the thermal action which takes place between the cutter and the material under machining, resulting in plastic deformation of the material occurring at high cutting speeds.

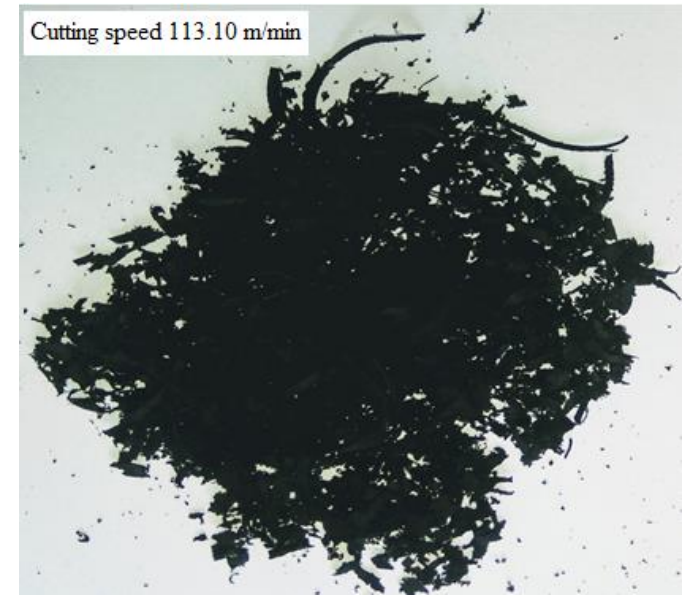

(a)

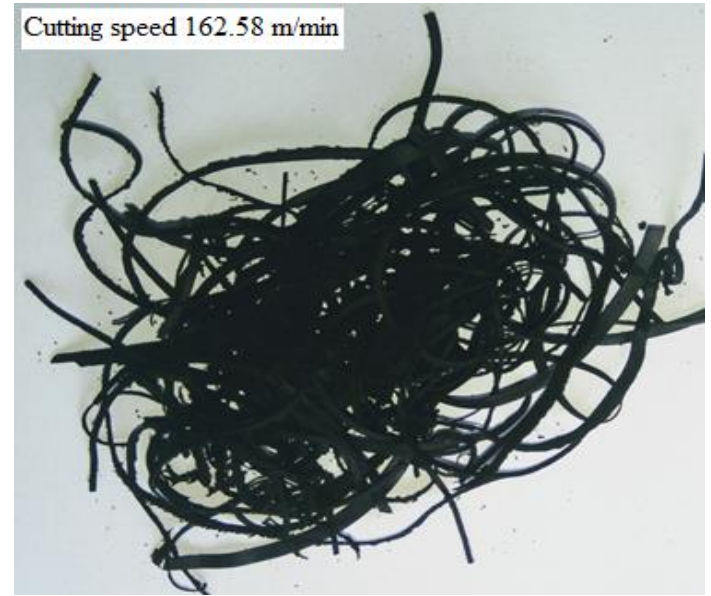

(b)

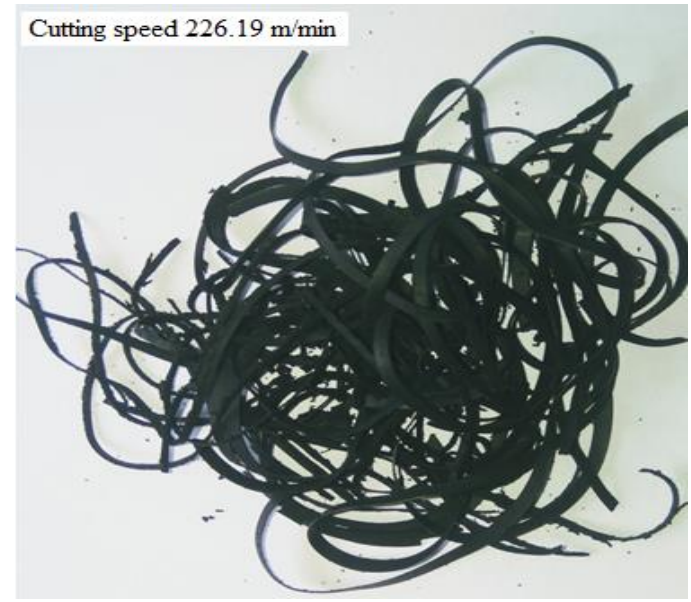

(c)

Figure 7. Chips shape in low temperature condition at three levels of cutting speed of (a) 113.10 , (b) 162.58 and; (c) $226.19 \mathrm{~m} / \mathrm{min}$.

\section{CONCLUSION}

An innovative methodology to improve machining of nitrile rubber has been carried out. Based on the experimental study, results indicated that the proportion increase in cutting force, radial force and feed force at low-temperature machining compared to dry was 
$11.9 \%, 17.08 \%$ and $18.83 \%$ at cutting speed $226.19 \mathrm{~m} / \mathrm{min}$, tool feed $0.5 \mathrm{~mm} / \mathrm{rev}$ and depth of cut $1 \mathrm{~mm}$. It was also detected that in low-temperature machining, the increase in machining forces was reduced at high speed. The fraction reduction in cutting force, radial force and feed force of low-temperature machining compared to dry when the cutting speed increased from $162.58 \mathrm{~m} / \mathrm{min}$ to $226.19 \mathrm{~m} / \mathrm{min}$, tool feed $0.5 \mathrm{~mm} / \mathrm{rev}$ and depth of cut $1 \mathrm{~mm}$ was $36.19,6.08$ and $23.3 \%$. This concludes that a remarkable decrease in cutting force value can be acquired by adopting low-temperature cooling. Preferred continuous ribbon-like long chips were found in low-temperature machining consequently signifying improved surface finish. The easy flow of chips over the tool surface was observed in low temperature machining, as that of ambient machining results improving the machinability. The cutting forces acquired for low-temperature machining were comparatively high even though merits like continuous chips formation, friction at chip-tool interface decreases, reducing tool wear and environmental benefits.

\section{ACKNOWLEDGEMENT}

The authors would like to express their appreciation and obligation to Manipal Academy of Higher Education (MAHE) for providing laboratory facilities.

\section{REFERENCES}

[1] Jin M, Murakawa M. High-speed milling of rubber- fundamental experiments and considerations for improvement of work accuracy. Journal of the Japan Society for Precision Engineering, 1998; 64 (6): 897-901.

[2] Shih AJ, Lewis MA, Luo J, Strenkowski JS. Chip morphology and forces in end milling of elastomers. ASME Journal of Manufacturing Science and Engineering, 2004; 126: 124-130.

[3] Shih AJ, Lewis MA, Strenkowski JS. End milling of elastomers -fixture design and tool effectiveness for material removal. ASME Journal of Manufacturing Science and Engineering. 2004;126: 115-123.

[4] Dhar NR, Paul S, Chattopadhyay AB. Role of cryogenic cooling on cutting temperature in turning steel. ASME Journal of Manufacturing Science and Engineering. 2002;124:146-154.

[5] Dhar NR, Paul S, Chattopadhyay AB. The influence of cryogenic cooling on tool wear, dimensional accuracy and surface finish in turning AISI 1040 and E4340C steels. Wear, 2002; 249:932-942.

[6] Rodkwan S, Strenkowski AJ, Lewis MA. Machining of elastomers experimental and numerical investigation. NSF Design, Service and Manufacturing Grantees and Research Conference Birmingham, Alabama.2003.

[7] ASTM D1566-00. Standard terminology relating to rubber, American Society for Testing of Materials; 2000.

[8] Harper CA. Handbook of plastics, elastomers and composites. 4th ed. McGrawHill;1996.

[9] Nayak R, Shetty R. Experimental and finite element analysis on chip formation mechanism in machining of elastomers. Bonfring International Journal of Industrial Engineering and Management Science. 2012;.2:10-13. 
[10] Nayak R, Shetty R. Cutting force and surface roughness in cryogenic machining of elastomer. International Journal of Mechanical Engineering and Technology. 2014; 5: 151-156.

[11] Saha A. Empirical modelling of machining parameters for turning operations using multiobjective Taguchi method. International Journal of Automotive and Mechanical Engineering. 2017;14 (3): 4448-4461.

[12] Boothroyd G. Fundamentals of metal machining and machine tools, 2nd ed. McGraw-Hill Book Company, New York; 1985.

[13] Yildiz Y, Nalbant M. A review of cryogenic cooling in machining processes. International Journal of Machine Tools \& Manufacture. 2008; 28: 947-964.

[14] Ramakoteswara Rao V, Ramanaiah N, Srinivasa Rao M, Sarcar MMM, Kartheek G. Optimisation of process parameters for minimum volumetric wear rate on AA7075-TiC metal matrix composite. International Journal of Automotive and Mechanical Engineering. 2016; 13:3669-80.

[15] Putza M, Dixa M. Neuberta M. Schmidtb G. Wertheimb R. Investigation of Turning Elastomers Assisted with Cryogenic Cooling. Procedia CIRP 40. 2016; $631-636$. 